\title{
AN INTEGRATED APPROACH FOR FATIGUE LIFE ESTIMATION BASED ON CONTINUUM MECHANICS THEORY AND GENETIC ALGORITHM
}

\section{Kamal and M.M. Rahman}

\author{
Faculty of Mechanical Engineering \\ Unviersiti Malaysia Pahang, 26600 Pekan, Pahang, Malaysia \\ Email: mustafizur@ump.edu.my \\ Phone: +6094246239; Fax: +6094246222
}

\begin{abstract}
This paper presents the performance analysis of a newly proposed fatigue estimation model. Research for fatigue estimation methods is focused on developing the capability to handle complex multiaxial loading conditions. This study focuses on an attempt to develop a new fatigue life estimation model using the concepts of continuum mechanics with a critical plane based approach. A genetic algorithm is utilized to estimate the coefficients of stress and strain components. Experimental data for fatigue lives for EN3B steel alloy for in-phase and out-of-phase loading conditions are used to calibrate and analyze the accuracy of the proposed model. Finite element analysis is used to determine an experimental fatigue life of EN3B steel alloy published in literature for validation. The proposed model is easy to implement and does not require the determination of new material constants and material properties. Fatigue life prediction from the proposed model shows good agreement with published results for in-phase and out-of-phase multiaxial loading.
\end{abstract}

Keywords: Multiaxial fatigue; critical plane method; continuum mechanics; genetic algorithm; EN3B steel alloy.

\section{INTRODUCTION}

Fatigue life estimation has become a critical feature for the performance analysis of mechanical structures since Wohler's experiments performed in the late $19^{\text {th }}$ century $[1$, 2]. Since then, a lot of research has been carried out in order to assess and analyze the effects of time-dependent loadings on the fatigue life of mechanical components [3-5]. Estimation of fatigue life in real-life components and structures is a more complex process as it involves a large number of variables or parameters so as to avoid early failures [6-9]. The consistency of any technique used for fatigue life estimation depends on many factors, such as stress concentration, degree of multiaxiality in the stress field, and the ability to model the damage caused by non-zero superimposed static stresses $[10,11]$. With cyclic and random multiaxial loading conditions it is more complicated to estimate the fatigue life of a component or a structure, as the material damage is caused by all the stress components as well as their time-dependent variations $[10,12]$. In order to obtain results that are more accurate and near to real-life scenarios, these fatigue life estimation techniques must be assessed using experimental data acquired in accordance with the pertinent standard codes [6, 10, 13-15]. The stress analysis is conducted to correctly estimate fatigue damage by directly post-processing simple linear elastic finite element models [16, 17]. Proportional and non-proportional multiaxial 
loads are a common occurrence in mechanical components and structures [18]. The multiaxial stress state can occur even under uniaxial loads, although typically in-phase, due to geometric constraints at notches. Various industries like aerospace, power generation and automotive frequently encounter multiaxial load and stress states $[5,18$, 19]. Research for developing new fatigue estimation models is continuously underway, but a universal model has not yet been developed for the comprehensive description of fatigue phenomena [4]. This study is focused on developing a new method based on a genetic algorithm for fatigue life estimation capable of handling multiaxial loading conditions.

\section{METHODS AND MATERIALS}

The continuum mechanics approach is used for the proposed method, in which evolution equations, i.e., incremental evolution of damage, are used contrary to the traditional damage per cycle method. The continuum theory itself contains damage accumulation during arbitrary load histories and it thereby avoids cycle counting techniques [20]. Long and random time histories are used to perform fatigue assessment when close-to-real loading conditions are required. Therefore the application of cycle counting methods leads to an over-complicated lengthy solution, which cannot be applied in practical engineering analysis [21]. In a similar study, an endurance function model was developed using a continuum mechanics approach [6]. In this research, a dimensionally balanced equation was proposed based on stress invariants. But the limitation of the model was the lack of information about the location of the critical plane, so the model was limited only to the crack initiation portion of total fatigue life. In order to develop an expression defining the proposed fatigue parameter, the stress / strain parameters needed to determine the state of material under load are identified from models already published in the literature. Strain-based models are considered for this study because of their robustness and ability to capture plasticity during loading. The models under study have either gained some degree of acceptance or are representative of a larger group of related models [22].

Brown, Miller and Kandil [23, 24], proposed a model based on cyclic shear and normal strain on the plane of maximum shear to define the stress parameter shown in Eq. (1) [25]. Cyclic shear strains nucleate the cracks while normal strains assist in their growth.

$$
\frac{\Delta \gamma_{\max }}{2}+S \Delta \varepsilon_{n}=(1.3+0.7 S) \frac{\sigma_{f}^{\prime}-2 \sigma_{n, \text { mean }}}{E}\left(2 N_{f}\right)^{b}+(1.5+0.5 S) \varepsilon_{f}^{\prime}\left(2 N_{f}\right)^{c}
$$

where $\Delta \gamma_{\max }$ is the maximum shear strain range, $\Delta \varepsilon_{\mathrm{n}}$ is the normal strain range on the plane experiencing $\Delta \gamma_{\max }, \mathrm{S}$ is a material dependent parameter representing the influence of normal strain on material crack growth, $\mathrm{N}_{\mathrm{f}}$ is fatigue life, $\sigma_{\mathrm{f}}, \varepsilon_{\mathrm{f}}, \mathrm{E}, \mathrm{b}, \mathrm{c}$ are material properties having their usual meanings.

Fatemi and Socie [26], based on the work of Brown and Miller, proposed to replace the normal strain term by the normal stress, as shown in Eq. (2). They argued that mean stress and non-proportional hardening effects can be captured by using normal stress. Critical plane models that include only strain terms cannot reflect the effect of mean stress or strain path dependent hardening. 


$$
\frac{\Delta \gamma}{2}\left(1+k \frac{\sigma_{n, \max }}{\sigma_{y}}\right)=\frac{\tau_{f}^{\prime}}{G}\left(2 N_{f}\right)^{p \gamma}+\gamma_{f}^{\prime}\left(2 N_{f}\right)^{c \gamma}
$$

where $\Delta \gamma$ is shear strain range, $\sigma_{n, \max }$ is normal shear stress on the plane from planes having maximum $\Delta \gamma, \mathrm{k}$ is a material sensitivity factor, $\sigma_{\mathrm{y}}$ is yield strength, $\mathrm{N}_{\mathrm{f}}$ is fatigue life, $\tau_{\mathrm{f}}, \gamma_{\mathrm{f}}, \mathrm{G}, \mathrm{b}_{\gamma}, \mathrm{c}_{\gamma}$ are material properties having their usual meanings.

Smith, Watson [27], revisited by Ince and Glinka [28], proposed a fatigue model for materials that primarily fail by crack growth on the planes of maximum tensile strain and stress. The proposed relationship includes both the cyclic strain range and the maximum stress expressed in Eq. (3). For multiaxial loading, the SWT parameter is based on the principal strain range $\Delta \varepsilon_{1}$, and maximum stress on the principal strain range plane, $\sigma_{n, \max }$. The stress term is used for describing multiaxial loading and nonproportional hardening effects.

$$
\sigma_{n, \max } \frac{\Delta \varepsilon_{1}}{2}=\frac{\sigma_{f}^{\prime 2}}{E}\left(2 N_{f}\right)^{2 b}+\sigma_{f}^{\prime} \varepsilon_{f}^{\prime}\left(2 N_{f}\right)^{p+c}
$$

Eq. (3) presented a virtual strain energy (VSE) model, which is a critical plane model, as work quantities are defined for specific planes within the material. For multiaxial loading, VSE considers two possible failure modes: a mode for tensile failure and a mode for shear failure. Failure is expected to occur on the plane having the maximum VSE quantity $\Delta \mathrm{W}$. For mode I tensile failure, VSE is computed as $\Delta \mathrm{W}_{\mathrm{I}}$, by first identifying the plane of maximum axial work with shear work added on the plane, as shown in Eq. (4). Similarly, $\Delta \mathrm{W}_{\mathrm{II}}$ (for mode II, shear failure) is computed by first identifying the plane of maximum shear work and the axial work component added on the plane, as in Eq. (5).

$$
\begin{gathered}
\Delta W_{I}=\left(\Delta \sigma_{n} \Delta \varepsilon_{n}\right)_{\max }+(\Delta \tau \Delta \gamma)=4 \sigma_{f}^{\prime} \varepsilon_{f}^{\prime}\left(2 N_{f}\right)^{p+c}+\frac{4 \sigma_{f}^{\prime 2}}{E}\left(2 N_{f}\right)^{2 b} \\
\Delta W_{I I}=\left(\Delta \sigma_{n} \Delta \varepsilon_{n}\right)+(\Delta \tau \Delta \gamma)_{\max }=4 \tau_{f}^{\prime} \gamma_{f}^{\prime}\left(2 N_{f}\right)^{p \gamma+c \gamma}+\frac{4 \gamma_{f}^{\prime 2}}{G}\left(2 N_{f}\right)^{2 b \gamma}
\end{gathered}
$$

Chu [29] proposed a similar model to combine shear and normal work. To include the effects of mean stress he replaced the stress ranges with maximum stresses, as in Eq. (6).

$$
\Delta W=\left(\sigma_{n, \max } \frac{\Delta \varepsilon}{2}+\tau_{n, \max } \frac{\Delta \gamma}{2}\right)_{\max }=1.02 \frac{\sigma_{f}^{\prime 2}}{E}\left(2 N_{f}\right)^{2 b}+1.04 \sigma_{f}^{\prime} \varepsilon_{f}^{\prime}\left(2 N_{f}\right)^{p+c}
$$

As per study of the above-mentioned models, the normal $(\Delta \varepsilon)$ and shear $(\Delta \gamma)$ strain ranges are identified so that plasticity induced during the applied loading can be captured. Mean stress effects and material hardening behavior are included for fatigue life estimation through the maximum and mean normal and shear stresses $\left(\sigma_{\max }, \tau_{\max }\right.$, $\left.\sigma_{\mathrm{m}}, \tau_{\mathrm{m}}\right)$. The newly proposed model is studied for the zero and positive mean, as well as in-phase and out-of-phase tension torsion loading, against the experimental fatigue life on a standard notched specimen. 


\section{PROPOSED MULTIAXIAL FATIGUE MODEL EQUATIONS}

The complex interaction of load and time can be taken as a cause of fatigue failure, as loads may be monotonic, steady, variable, uniaxial or multiaxial [2]. The fatigue failure of a structural component is characterized by crack nucleation and crack propagation occurring at critical points of the structural component until the final collapse [6]. Cracks start on the localized shear plane around high stress concentrations, such as persistent slip bands, inclusions, porosity, or discontinuities. The localized shear plane usually occurs at the surface or within grain boundaries. Once nucleation occurs and cyclic loading continues, the crack tends to grow along the plane of maximum shear stress and through the grain boundary [1].

In the present model, failure is assumed to occur with the start of crack nucleation, and crack propagation is on a plane known as the critical plane, identified according to the considered criteria. The criteria for critical planes identification may be the plane having the maximum strain or stress range, or a plane with the maximum fatigue parameter value or a plane with the maximum variance of shear stress, etc. A similar configuration to that of the endurance function model proposed by Brighenti and Carpinteri [6] has been adopted to formulate the proposed evolution equations for the newly proposed model. Damage parameter $\mathrm{P}$ is defined in terms of strain ranges $(\Delta \gamma$, $\Delta \varepsilon)$, maximum shear and maximum normal stresses $\left(\tau_{\max }, \sigma_{n, \max }\right)$ determined on the critical plane, as shown by Eq. (7)

$$
P=a_{1}\left(\Delta \gamma \cdot \tau_{\max }\right)+a_{2}\left(\Delta \varepsilon \cdot \sigma_{n, \max }\right)-\frac{\sigma_{L}^{2}}{E}-e v
$$

where $a_{1}, a_{2}$ and $\sigma_{\mathrm{L}}$ are material constants determined by calibrating the model against a known fatigue life and load history.

Parameter $e v$ is defined by Eq. (8) describing the modification of parameter $\mathrm{P}$ with stress history. This can be understood with the concept of isotropic and kinematic hardening of materials. The parameter is defined with criteria that, if during a load step $\Delta \mathrm{P}>0$ (i.e. material was damaged in this load step), then $e v$ is defined by Eq. (8) and if $\Delta \mathrm{P} \leq 0$ (i.e. no damage occurred in this load step), then $e v$ for that step is zero $(e v=0)$.

$$
e v=V . d P^{m}\left(\frac{\tau_{\max }-\tau_{m}}{E}\right)\left(\frac{\sigma_{\max }-\sigma_{m}}{E}\right)
$$

where $V$ is a material parameter and $m$ is the power of increment of parameter $\mathrm{P}$.

Eq. (9) shows a relationship between $D_{n}$, i.e. damage for load step ' $n$ ', and damage parameter $\mathrm{P}$ and $\Delta \mathrm{P}$, i.e. change in $\mathrm{P}$ with each load step, where $K$ and $R$ are material parameters.

$$
D_{n}=K \cdot P^{R} . \Delta P
$$

Damage is accumulated on a monitored location most susceptible to fatigue failure, and the stress-strain state at each load step is evaluated with respect to mathematical function P, Eq. (7). For a certain load step where the stress-strain state results in a value of $\mathrm{P}$ less than zero $(\mathrm{P} \leq 0)$, this will not result in damage to the material. In other words, a damage increment will occur only when stress-strain state leads to $\mathrm{P}>1$. Additionally, 
for a damage increment to occur, the change in parameter $\mathrm{P}$ should be positive $(\Delta \mathrm{P}>0)$, i.e., the value of $\mathrm{P}$ should be increased in the current load step from the previous one to consider any damage to occur in the current load step. The total damage $\mathrm{D}$ at the point of the component under study is evaluated as the accumulated function of damage increments $D_{n}$ at each load step, so at each load step of the fatigue process the damage increment is equal to or greater than zero, i.e. $\mathrm{D}_{\mathrm{n}}$, and consequently the material damage $\mathrm{D}$ is a non-decreasing positive function during the load history [20]. Complete damage will occur when $D$ reaches unity $(D=1)$. Figure 1 shows the flow chart of the fatigue life estimation process by the calibrated proposed model.

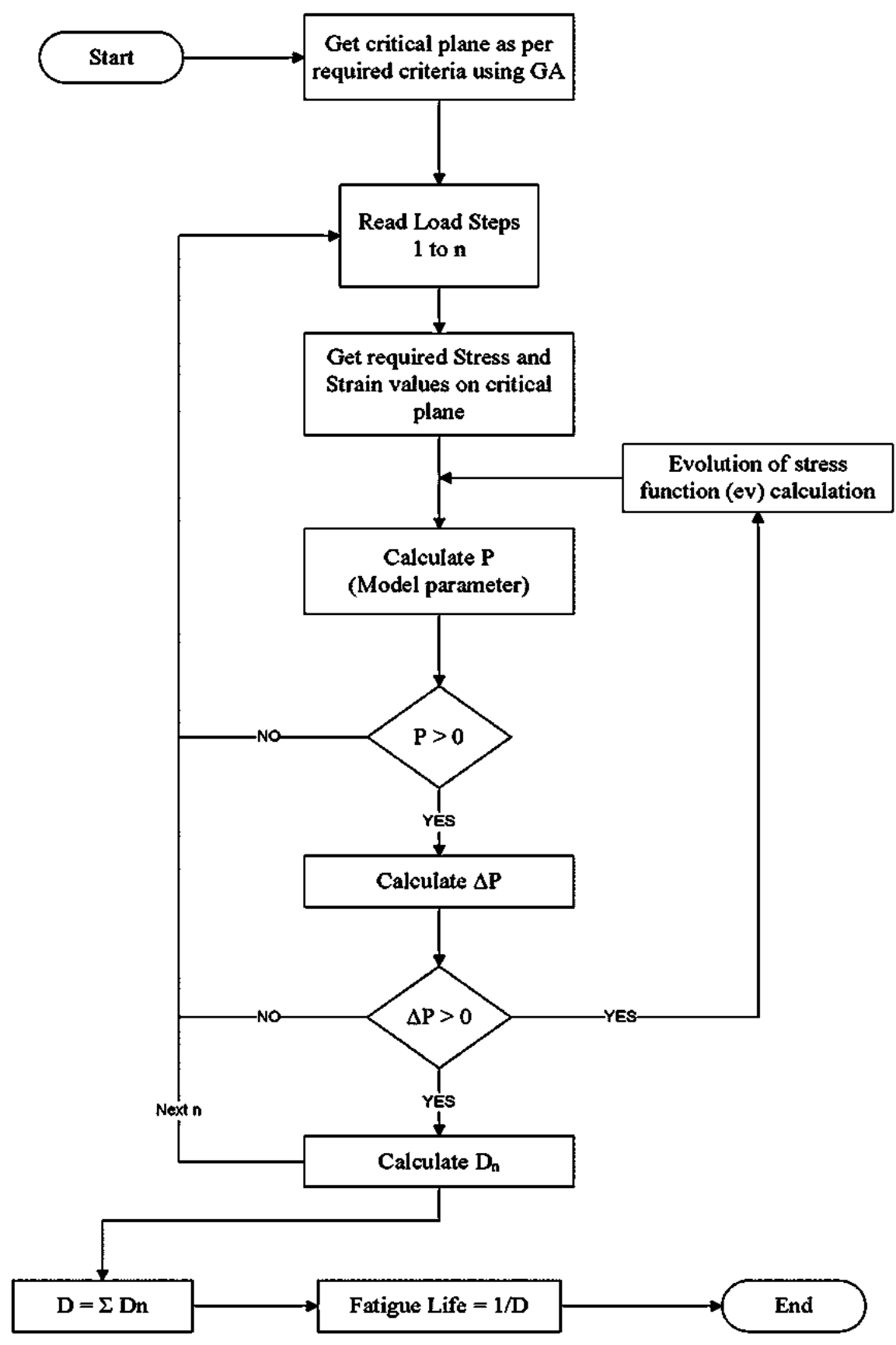

Figure 1. Fatigue life estimation process flow chart for proposed model. 


\section{MODEL CALIBRATION USING GA}

The proposed model can be used to estimate fatigue life for complex in- and out-ofphase loading conditions, if all the parameters are calibrated according to a known load and fatigue life. In the present section, a genetic algorithm (GA) with MOGA-II (Multi Objective Genetic Algorithm) is used to calibrate the model parameters $\left(\mathrm{a}_{1}, \mathrm{a}_{2}, \sigma_{\mathrm{L}}, \mathrm{V}, \mathrm{m}\right.$, $\mathrm{K}, \mathrm{R})$. The GAs have some advantages with respect to classical techniques, as they allow us to handle problems with multiple minima and non-convexity properties, thus avoiding numerical instability and missing of the global optimum [30]. A GA operates by simulating the natural evolution process of life [31]. These algorithms are used to minimize / maximize an objective function chosen to solve a given problem. This method can be used to optimize the model parameters according to the known loading with fatigue life for the applied loading [32-34].

The advantage of using a GA for the proposed model is that a GA can handle various objective functions and large population sets. It uses basic concepts like random number generation, choice, switching and combinations of such generated numbers, to get a new population which performs better than the previous generation [35]. This process is repeated iteratively until the required tolerance is achieved and thus the optimal condition can be achieved [36]. In the present study, the objective function is defined as damage prediction error err, as in Eq. (10):

$$
\text { err }=\mathrm{D}-\mathrm{D}_{\mathrm{FL}}
$$

where $\mathrm{D}$ is the total cumulative damage after each load step and $\mathrm{D}_{\mathrm{FL}}$ is the inverse of fatigue life at a known loading which is being used for calibration. The values of model parameters used for characterization of the damage mechanics approach are now found by minimizing the objective function err using a GA procedure [37].

\section{FINITE ELEMENT ANALYSIS}

Structural analysis is performed through Finite Element Analysis (FEA) to determine the stress / strain state in the specimen geometry of EN3B steel alloy for each load set for which experimental fatigue life is published in the literature [10], as shown in Figure 2(a), with material properties in Table 1. The finite element model is developed utilizing the ANSYS software with 10-node tetrahedral elements [38, 39]. Dense mesh at the notch root is maintained by the sphere of influence technique, as shown in Figure 2(b). As plastic deformation has to be considered, a non-linear analysis is performed including a full stress-strain curve in the material model of EN3B. Force and moment loads are applied such as to generate normal and shear stress at the net area, as mentioned in Table 2 and the specimen model is shown in Figure 2(c). The details of applied loads and respective fatigue life taken from the literature [10] are reported in Table 2. The notch root is considered to be the critical point for crack initiation, and to predict the fatigue life as closely to the experimental values as possible, the state of stress and strain at the notch root is used in the estimation of fatigue life. 


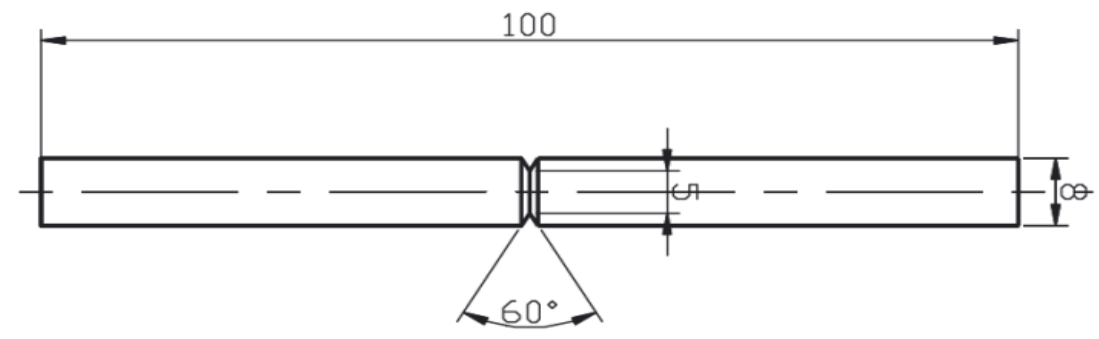

(a) Dimensions of specimen [10]

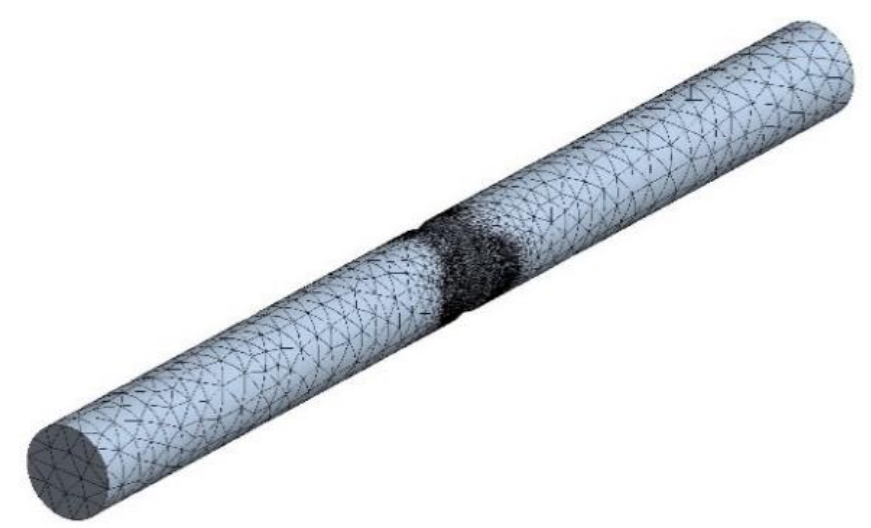

(b) FEA model

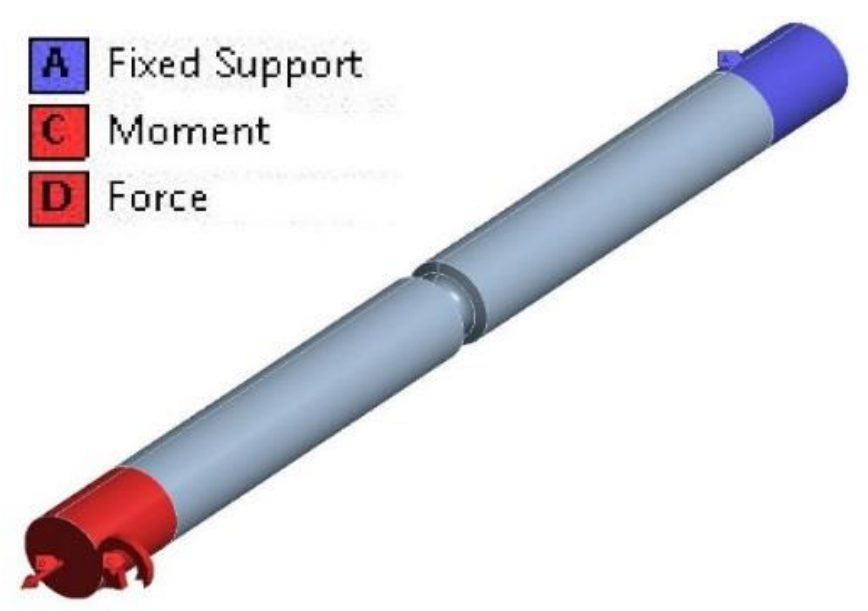

(c) Applied loads on specimen

Figure 2. EN3B test specimen and FEA model.

Table 1. Mechanical properties of EN3B steel [40].

\begin{tabular}{cccccc}
\hline $\begin{array}{c}\text { Material } \\
\text { name }\end{array}$ & $\begin{array}{c}\text { Young's } \\
\text { Modulus }\end{array}$ & $\begin{array}{c}\text { Yield } \\
\text { stress } \\
(\mathrm{MPa})\end{array}$ & $\begin{array}{c}\text { Ultimate } \\
\text { tensile } \\
\text { strength }(\mathrm{MPa})\end{array}$ & $\begin{array}{c}\text { Cyclic strain } \\
\text { hardening } \\
\text { exponent, } \mathrm{n}\end{array}$ & $\begin{array}{c}\text { Cyclic strength } \\
\text { coefficient, K' } \\
\text { (MPa) }\end{array}$ \\
\hline EN3B & 208.5 & 571 & 622 & 0.1635 & 890.7 \\
\hline
\end{tabular}




\section{RESULTS AND DISCUSSION}

\section{Mesh Independence Study}

For the developed FEA model, to find a balanced performance between accuracy, solution time and storage of result files, a mesh dependence study has been performed [41, 42]. Maximum principal, von Mises, and Tresca stresses are observed for mesh convergence with the processing load depending on the number of nodes and elements. Figure 3 shows the result of the mesh sensitivity analysis. It can be seen that after a mesh size of $0.175 \mathrm{~mm}$, the values of stresses change by a negligible amount of 1-3 $\mathrm{MPa}$, but there is an exponential rise in the number of nodes and elements, which will result in increased processor time and storage requirements without much increase in the accuracy of the stress results. Thus, to get the balanced performance, a mesh size of $0.175 \mathrm{~mm}$ is selected for meshing the model.

\section{Application of Proposed Model}

The EN3B steel alloy specimen (Figure 2) is tested against in-phase and out-of-phase loading conditions published in the literature (Table 2). The proposed model is developed using ANSYS internal programming language. The algorithm identifies the critical plane by identifying the plane with the maximum value of the critical plane variable $\mathrm{crtpl}$, Eq. (11). Normal and shear stress and strain ranges $\left(\sigma_{\mathrm{n}, \max }, \tau_{\max }, \Delta \varepsilon, \Delta \gamma\right)$ with respect to the critical plane are calculated. Now, for calibration loads $\mathrm{CP}_{1}$ and $\mathrm{CP}_{2}$ (Table 2), for each set the calculated stresses and strains are used to determine the model parameters using GA procedures (MOGA-II). The fatigue life value is calculated for the remaining loads other than that used for calibration, using the proposed damage evolution equations in Eqs. (7)-(9). To implement this, code is developed in APDL which uses the model parameters calculated earlier and estimates the fatigue life for the current applied loading.

$$
\operatorname{crtpl}=\left(\Delta \gamma \cdot \tau_{\max }\right)+\left(\Delta \varepsilon \cdot \sigma_{n, \max }\right)
$$

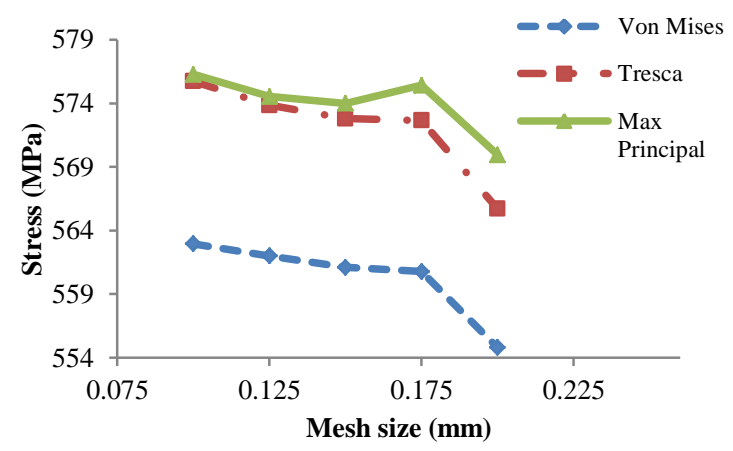

(a)

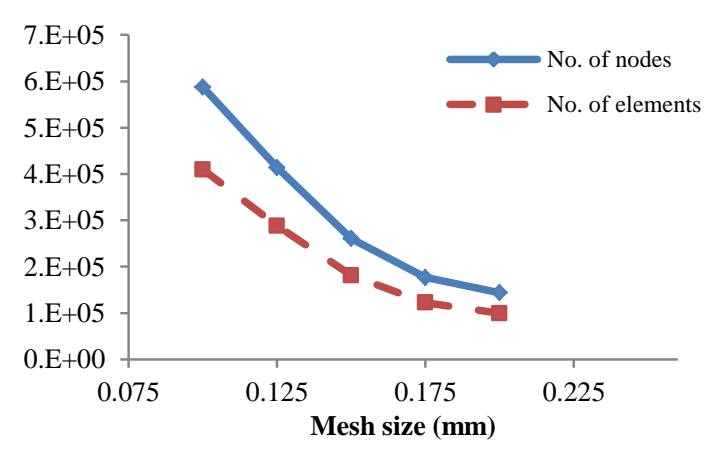

(b)

Figure 3. (a) Mesh size versus calculated FEA stresses; (b) mesh size versus no. of nodes and elements of FEA model. 
Table 2. Experimental loads and fatigue life of EN3B specimen having notch radius $1.25 \mathrm{~mm}[10]$.

\begin{tabular}{|c|c|c|c|c|}
\hline \multirow{2}{*}{$\begin{array}{l}\text { Normal } \\
\text { stress at net } \\
\text { area }\left(\sigma_{\mathrm{a}}\right) \\
(\mathrm{MPa}) \\
\end{array}$} & \multirow{2}{*}{$\begin{array}{c}\text { Shear } \\
\text { stress at } \\
\text { net area } \\
\left(\tau_{\mathrm{a}}\right)(\mathrm{MPa}) \\
\end{array}$} & \multirow{2}{*}{$\begin{array}{l}\text { Experimental } \\
\text { fatigue life } \\
\text { (cycles) }\end{array}$} & \multicolumn{2}{|c|}{ Predicted fatigue life (cycles) } \\
\hline & & & $\begin{array}{c}\text { Two calibration } \\
\text { points }\left(\mathrm{CP}_{1} \&\right. \\
\left.\mathrm{CP}_{2}\right)\end{array}$ & $\begin{array}{l}\text { Calibration points } \\
\left(\mathrm{CP}_{1}-\mathrm{CP}_{3} \& \mathrm{CP}_{3}-\right. \\
\left.\mathrm{CP}_{2}\right)\end{array}$ \\
\hline \multicolumn{5}{|c|}{$\mathrm{R}=-1$ and phase $=0$} \\
\hline $180_{(\mathrm{CP} 2)}$ & 103.9 & 2174897 & 1786431 & --- \\
\hline 190 & 109.7 & 1400006 & 807181 & --- \\
\hline 200 & 115.5 & 437907 & 445531 & --- \\
\hline 230 & 132.8 & 188480 & 135909 & --- \\
\hline 259.6 & 155.9 & 82952 & 58167 & --- \\
\hline $275_{(\mathrm{CP} 1)}$ & 158.8 & 46254 & 42878 & --- \\
\hline \multicolumn{5}{|c|}{$\mathrm{R}=-1$ and phase $=90$} \\
\hline $200_{(\mathrm{CP} 2)}$ & 115.5 & 2100000 & 1869827 & --- \\
\hline 230 & 132.8 & 245935 & 184465 & --- \\
\hline 250 & 144.3 & 79328 & 79388 & --- \\
\hline 260 & 150.1 & 314817 & 68753 & --- \\
\hline 270 & 155.9 & 59622 & 42365 & --- \\
\hline $285_{(\mathrm{CP} 1)}$ & 164.5 & $31700 / 36976$ & 28869 & --- \\
\hline \multicolumn{5}{|c|}{$\mathrm{R}=0$ and phase $=0$} \\
\hline $150_{(\mathrm{CP} 2)}$ & 150 & 844615 & 759879 & --- \\
\hline 160 & 160 & 370618 & 169407 & --- \\
\hline 165 & 165 & 249286 & 119982 & --- \\
\hline 170 & 170 & 110056 & 86524 & --- \\
\hline 180 & 180 & 28108 & 51294 & --- \\
\hline $190_{(\mathrm{CP} 1)}$ & 190 & 34298 & 31123 & --- \\
\hline \multicolumn{5}{|c|}{$\mathrm{R}=0$ and phase $=90$} \\
\hline $145_{(\mathrm{CP} 2)}$ & 145 & 2581210 & 2303300 & 2303300 \\
\hline 150 & 150 & 2500000 & 1317299 & 839787 \\
\hline 155 & 155 & 367445 / & 704303 & 363447 \\
\hline 160 & 160 & $\begin{array}{c}77755 \text { / } 304439 \\
\text { / } 2500000\end{array}$ & 444139 & 195065 \\
\hline $170_{(\mathrm{CP} 3)}$ & 170 & 112944 & 230905 & 81354 \\
\hline 180 & 180 & 49200 & 131045 & 58199 \\
\hline 190 & 190 & 52000 & 84352 & 45785 \\
\hline 200 & 200 & 67873 & 48555 & 31242 \\
\hline $235_{(\mathrm{CP} 1)}$ & 135.7 & 59243 & 53559 & 53559 \\
\hline
\end{tabular}

Note: $\mathrm{CP}_{1}, \mathrm{CP}_{2}$ and $\mathrm{CP}_{3}$ are first, second and third calibration points for model coefficients determination

The proposed model is implemented by performing FEA to calculate the stress state at the notch root surface of the specimen, as the notch root is the most susceptible region for failure. Then stress components on the critical plane are calculated and the GA tool with Eqs. (7)-[43] is used to determine the coefficients of the proposed model for fatigue life estimation. Fatigue life is predicted with two and three calibration points $\mathrm{CP}_{1}, \mathrm{CP}_{2}$ and $\mathrm{CP}_{3}$, where the coefficients for each load step are interpolated between the 
coefficients of the calibration points (Table 2). Results from the experimental fatigue life values from the literature (Table 2) [10] and predictions made by the proposed model with one and two calibration points are reported side by side in Table 3 .

Table 3. Predicted fatigue life of EN3B steel.

\begin{tabular}{|c|c|c|c|}
\hline $\begin{array}{l}\text { Normal stress at net } \\
\text { area }\left(\sigma_{\mathrm{a}}\right)(\mathrm{MPa})\end{array}$ & $\begin{array}{c}\text { Shear stress at net } \\
\text { area }\left(\tau_{\mathrm{a}}\right)(\mathrm{MPa})\end{array}$ & $\begin{array}{c}\text { Experimental } \\
\text { fatigue life (cycles) }\end{array}$ & $\begin{array}{l}\text { Predicted fatigue } \\
\text { life (cycles) }\end{array}$ \\
\hline & & & $\begin{array}{c}\text { Two calibration } \\
\text { points }\left(\mathrm{CP}_{1} \&\right. \\
\left.\mathrm{CP}_{2}\right)\end{array}$ \\
\hline \multicolumn{4}{|c|}{$\mathrm{R}=-1$ and phase $=0$} \\
\hline $180_{(\mathrm{CP} 2)}$ & 103.9 & 2174897 & 1786431 \\
\hline 190 & 109.7 & 1400006 & 807181 \\
\hline 200 & 115.5 & 437907 & 445531 \\
\hline 230 & 132.8 & 188480 & 135909 \\
\hline 259.6 & 155.9 & 82952 & 58167 \\
\hline $275_{(\mathrm{CP} 1)}$ & 158.8 & 46254 & 42878 \\
\hline \multicolumn{4}{|l|}{$\mathrm{R}=-1$ and phase $=90$} \\
\hline $200_{(\mathrm{CP} 2)}$ & 115.5 & 2100000 & 1869827 \\
\hline 230 & 132.8 & 245935 & 184465 \\
\hline 250 & 144.3 & 79328 & 79388 \\
\hline 260 & 150.1 & 314817 & 68753 \\
\hline 270 & 155.9 & 59622 & 42365 \\
\hline $285_{(\mathrm{CP} 1)}$ & 164.5 & $31700 / 36976$ & 28869 \\
\hline \multicolumn{4}{|c|}{$\mathrm{R}=0$ and phase $=0$} \\
\hline $150_{(\mathrm{CP} 2)}$ & 150 & 844615 & 759879 \\
\hline 160 & 160 & 370618 & 169407 \\
\hline 165 & 165 & 249286 & 119982 \\
\hline 170 & 170 & 110056 & 86524 \\
\hline 180 & 180 & 28108 & 51294 \\
\hline $190_{(\mathrm{CP} 1)}$ & 190 & 34298 & 31123 \\
\hline \multicolumn{4}{|c|}{$\mathrm{R}=0$ and phase $=90$} \\
\hline $145_{(\mathrm{CP} 2)}$ & 145 & 2581210 & 2303300 \\
\hline 150 & 150 & 2500000 & 1317299 \\
\hline 155 & 155 & $367445 / 2000000$ & 704303 \\
\hline 160 & 160 & $\begin{array}{c}77755 / 304439 / \\
2500000\end{array}$ & 444139 \\
\hline $170_{(\mathrm{CP} 3)}$ & 170 & 112944 & 230905 \\
\hline 180 & 180 & 49200 & 131045 \\
\hline 190 & 190 & 52000 & 84352 \\
\hline 200 & 200 & 67873 & 48555 \\
\hline $235_{(\mathrm{CP} 1)}$ & 135.7 & 59243 & 53559 \\
\hline
\end{tabular}

For the case of the load set with $\mathrm{R}=-1$ and phase $=0$, it is observed that the fatigue lives predicted by the proposed fatigue life model are on the conservative side. The predicted life for the load point of $200 \mathrm{MPa}$ normal stress is higher than the experimental life. This increase in the predicted fatigue life for the said load point is due to the scatter in the experimental data, resulting in a deviation from the model behavior at other load points. The results from the proposed fatigue life model are in good agreement with the experimental data. For the case of the load set with $\mathrm{R}=-1$ and phase 
$=90$, the predicted fatigue life from the proposed fatigue life model is in good correlation with the experimental data. The results are conservative, i.e., the predicted fatigue life is lower than the experimental fatigue life, resulting in safe mechanical designs. The difference between the predicted fatigue life and the experimental data at the load point with $260 \mathrm{MPa}$ normal stress load is attributed to the scatter in the experimental data. This deviation in the data can also be observed in the plot showing the relationship between predicted and experimental data in Figure 4(b). For $260 \mathrm{MPa}$ normal stress load, the reported experimental fatigue life shows an offset from the general trend, confirming that the reported fatigue life at this load point is higher than expected, compared to fatigue lives from other load values. In general, the results of the predicted fatigue life from the proposed model are accurate with respect to the experimental data for the load set with $\mathrm{R}=-1$ and phase $=90$.

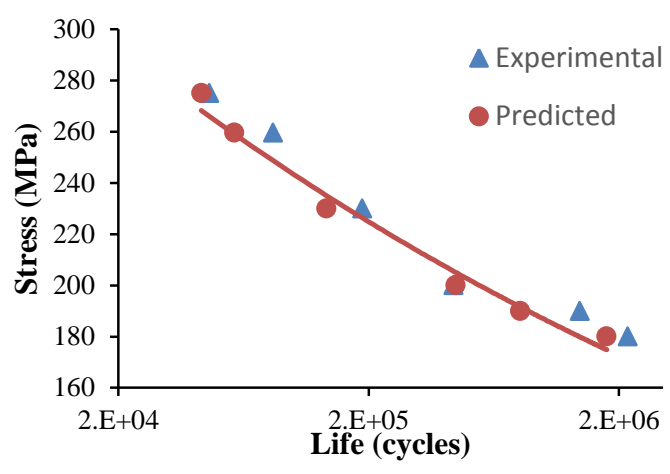

(a)

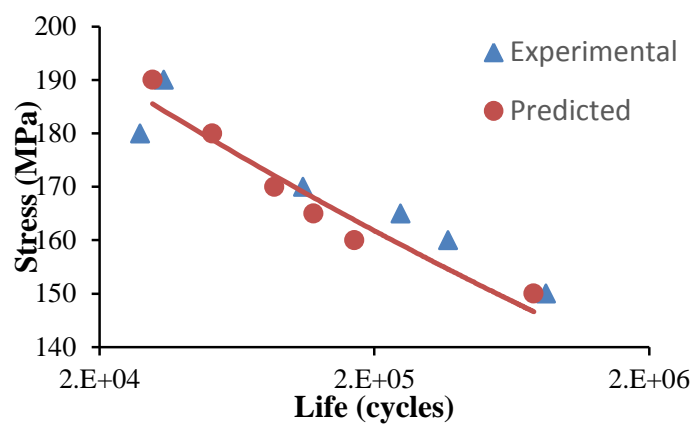

(c)

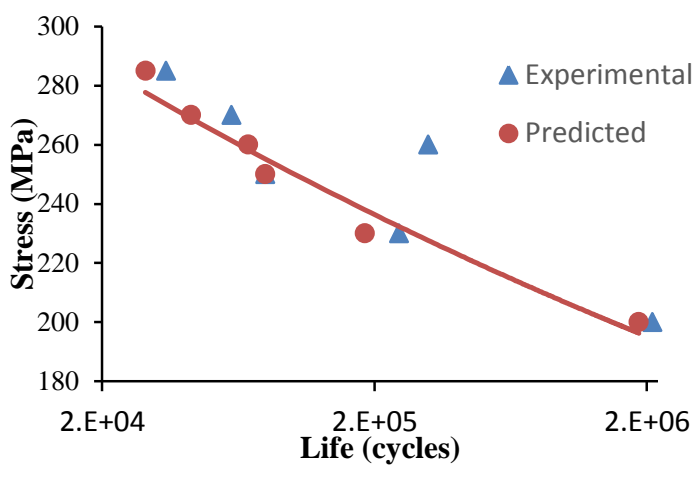

(b)

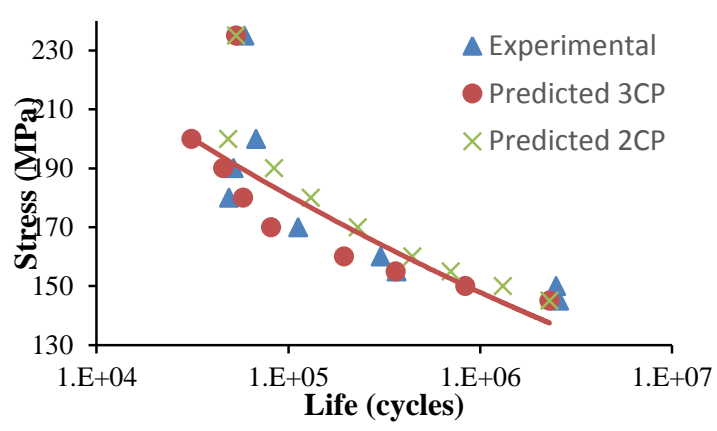

(d)

Figure 4. Predicted fatigue life (a) for $\mathrm{R}=-1$ and phase $=0^{\circ}$, (b) $\mathrm{R}=-1$ and phase $=90^{\circ}$, (c) $\mathrm{R}=0$ and phase $=0^{\circ}$, (d) $\mathrm{R}=0$ and phase $=90^{\circ}$.

For the load case of $\mathrm{R}=0$, phase $=0$, the results of predicted fatigue life are presented in Table 3. The results are on the conservative side as the predicted fatigue life is lower than the experimental fatigue life, which is generally favorable for safe designs. However, at the normal stress load value of $180 \mathrm{MPa}$, the experimentally obtained fatigue life is lower than the predicted life. This is attributed to scatter in the experimental data, as can be observed from Figure 4(c), and is not representative of the typical behavior of EN3B material with respect to other load points. For the remaining load values, the estimated fatigue life from the proposed model is in good agreement with the experimental data. For the load set with $\mathrm{R}=0$ and phase $=90$, the fatigue life is 
estimated using model coefficients determined from two as well as three calibration points. The results for predicted fatigue life compared with experimental fatigue life are presented in Table 3. The predicted fatigue life is plotted against the experimental fatigue life in Figure 4(d). The fatigue life predicted by interpolating the model coefficients between the two calibration points $\mathrm{CP}_{1}$ and $\mathrm{CP}_{2}$ is generally overestimated, especially in the region away from $\mathrm{CP}_{1}$ and $\mathrm{CP}_{2}$. A significant improvement in fatigue life prediction accuracy is observed when three-point calibration is used, with an additional calibration point $\mathrm{CP}_{3}$ at $170 \mathrm{MPa}$ load in the interpolation scheme. The predicted fatigue life resulting from the three-point calibration shows good agreement with the experimental fatigue life. The estimated fatigue lives provide a good averaged representation of the EN3B behavior, even with the scatter in the experimental results. Hence, it can be concluded that additional calibration points improve the fatigue life prediction accuracy. Higher fatigue life prediction efficiency can be achieved with few calibration points for a range of load magnitudes, thus requiring a lesser number of experimental results and leading to more cost-effective experimental testing for generating the calibration data. In future studies, the proposed model will be tested against more complex loading conditions.

\section{CONCLUSIONS}

In this study, a new fatigue life estimation model has been proposed using the continuum mechanics concepts and a genetic algorithm. Experimental fatigue lives for EN3B steel alloy for in-phase and out-of-phase loading conditions are used to calibrate and analyze the accuracy of the proposed model. The results show that the new model predicted fatigue life with good accuracy with respect to the experimental fatigue life in both types of load case. The proposed model predicts fatigue life in good agreement with published experimental data for in-phase and out-of-phase loads for zero mean and positive mean of loading stresses in the case of two calibration points. The case with three calibration points improved the accuracy of fatigue life estimation. Overall, the model is simple to apply, with good accuracy. A more detailed study is needed to examine the performance of the new model against more complex multiaxial and variable amplitude loading conditions.

\section{ACKNOWLEDGMENTS}

The authors would like to thank Universiti Malaysia Pahang for financial support under project no. RDU110332 and providing laboratory facilities.

\section{REFERENCES}

[1] Lee Y, Pan J, Hathaway R, Barkey M. Fatigue testing and analysis: Theory and practice. New York: Butterworth Heinemann; 2005.

[2] Stephens RI, Fatemi A, Stephens RR, Fuchs HO. Metal fatigue in engineering. New York: John Wiley and Sons, Inc.; 2000.

[3] Manson SS, Halford GR. Fatigue and durability of structural materials. Materials Park, Ohio: ASM International, Materials; 2006.

[4] Papuga J. A survey on evaluating the fatigue limit under multiaxial loading. International Journal of Fatigue. 2011;33:153-65. 
[5] Fatemi A, Shamsaei N. Multiaxial fatigue: An overview and some approximation models for life estimation. International Journal of Fatigue. 2011;33:948-58.

[6] Brighenti R, Carpinteri A. A notch multiaxial fatigue approach based on damage mechanics. International Journal of Fatigue. 2012;39:122-33.

[7] Ali N, Mustapa MS, Ghazali MI, Sujitno T, Ridha M. Fatigue life prediction of commercially pure titanium after nitrogen ion implantation. International Journal of Automotive and Mechanical Engineering. 2013;7:1005-13.

[8] Kamal M, Rahman MM, Sani MSM. Application of multibody simulation for fatigue life estimation. International Journal of Automotive and Mechanical Engineering. 2013;7:912-23.

[9] Kamal M, Rahman MM. Fatigue life estimation models: A state of art. International Journal of Automotive and Mechanical Engineering. 2014;9:1599608.

[10] Susmel L, Taylor D. The Modified Wohler Curve Method applied along with the Theory of Critical Distances to estimate finite life of notched components subjected to complex multiaxial loading paths. Fatigue and Fracture of Engineering Materials and Structures. 2008;31:1047-64.

[11] Rahman MM, Ariffin AK, Rejab MRM, Kadirgama K, Noor MM. Multiaxial fatigue behavior of cylinder head for a free piston linear engine. Journal of Applied Sciences. 2009;9:2725-34.

[12] Macha E, Niesłony A. Critical plane fatigue life models of materials and structures under multiaxial stationary random loading: The state-of-the-art in Opole Research Centre CESTI and directions of future activities. International Journal of Fatigue. 2012;39:95-102.

[13] Atzori B, Berto F, Lazzarin P, Quaresimin M. Multi-axial fatigue behaviour of a severely notched carbon steel. International Journal of Fatigue. 2006;28:485-93.

[14] Susmel L, Taylor D. A critical distance/plane method to estimate finite life of notched components under variable amplitude uniaxial/multiaxial fatigue loading. International Journal of Fatigue. 2012;38:7-24.

[15] Susmel L, Tovo R. Estimating fatigue damage under variable amplitude multiaxial fatigue loading. Fatigue and Fracture of Engineering Materials and Structures. 2011;33:1055-77.

[16] Bishop NWM, Sherratt F. Finite element based fatigue calculations. Netherlands: NAFEMS Ltd.; 2000.

[17] Kamal M, Rahman MM. Finite Element-Based Fatigue Behaviour of Springs in Automobile Suspension. International Journal of Automotive and Mechanical Engineering. 2014;10:1910-9.

[18] Rahman MM, Ariffin AK, Rejab MRM, Kadirgama K, Noor MM. Multiaxial fatigue behaviour of cylinder head for a free piston linear engine. Journal of Applied Sciences. 2009;9:2725-34.

[19] Rahman MM, Ariffin AK, Jamaludin N, Haron CHC. Vibration fatigue analysis of cylinder head of a new two-stroke free piston engine using finite element approach. Structural Integrity and Durability. 2005;1:121-9.

[20] Ottosen NS, Stenstrom R, Ristinmaa M. Continuum approach to high-cycle fatigue modeling. International Journal of Fatigue. 2008;30:996-1006.

[21] Nieslony A, Ruzicka M, Papuga J, Hodr A, Balda M, Svoboda J. Fatigue life prediction for broad-band multiaxial loading with various PSD curve shapes. International Journal of Fatigue. 2012;44:74-88. 
[22] Socie DF, Marquis GB. Multiaixal Fatigue. Warrendale, PA, USA: SAE; 2000.

[23] Brown MW, Miller KJ. Two decades of progress in the assessment of multiaxial low-cycle fatigue life. In: Amzallag C, Leis BN, Rabbe P, editors. Low-cycle fatigue and life prediction. West Conshohocken, PA: American Society for Testing and Materials; 1982. p. 482-99.

[24] Kandil FA, Brown MW, Miller KJ. Biaxial low-cycle fatigue fracture of 316 stainless steel at elevated temperatures. London: The Metals Society; 1982. p. 203-10.

[25] Jin L, Zhang Y, Dombrowski JP, Chen C-H, Pravatas A, Xu L, et al. $\mathrm{ZnO} / \mathrm{La}_{2} \mathrm{O}_{2} \mathrm{CO}_{3}$ layered composite: $\mathrm{A}$ new heterogeneous catalyst for the efficient ultra-fast microwave biofuel production. Applied catalysis B, Environmental. 2011;103:200-5.

[26] Fatemi A, Socie DF. A critical plane approach to multiaxial fatigue damage including out of phase loading. Fatgiue and Fracture of Engineering Materials and Structures. 1988;11:149-66.

[27] Smith KN, Watson P, Topper TH. A Stress-Strain function for the fatigue of metals. Journal of Materials. 1970;5:767-78.

[28] Ince A, Glinka G. A modification of Morrow and Smith-Watson-Topper mean stress correction models. Fatigue and Fracture of Engineering Materials and Structures. 2011;34:854-67.

[29] Chu CC. Fatigue damage calculation using the critical plane approach. Journal of Engineering Materials and Technology. 1995;117:41-9.

[30] Davis L. Handbook of genetic algorithms. New York: Van Nostrand Reinhold; 1991.

[31] Whitely D. A genetic algorithm tutorial. Statistics and Computing. 1994;4:6585.

[32] Clarich A, Russo R, Carriglio M. Multi-objective optimization with modefrontier interfaces for ansa and metapost. 4th ANSA \& $\mu$ ETA International Conference. Thessaloniki, Greece; 2011.

[33] Perillo M, Primavera V, Fuligno L, Fabbri G, Steenbergen C, Pasini N. Optimization and robustness of complex material model simulations with modeFRONTIER. 7th European LS-DYNA Conference. Salzburg, Austria. 2009; 1-10.

[34] modeFrontier. User manual.

[35] Franulovic M, Basan R, Prebil I. Genetic algorithm in material model parameters' identification for low-cycle fatigue. Computational Materials Science. 2009;45:505-10.

[36] Gantovnik VB, Anderson-Cook CM, Gürdal Z, Watson LT. A genetic algorithmwith memory for mixed discrete-continuous design optimization. Computer and Structures. 2003;81:2003-9.

[37] Brighenti R, Carpinteri A, Vantadori S. A genetic algorithm applied to optimisation of patch repairs for cracked plates. Computer Methods in Applied Mechanics and Engineering. 2006;196:466-75.

[38] Rahman MM, Kadirgama K, Noor MM, Rejab MRM, Kesulai SA. Fatigue life prediction of lower suspension arm using strain-life approach. European Journal of Scientific Research. 2009;30:437-50.

[39] Kamal M, Rahman MM, Sani MSM. Fatigue Life Prediction Using Simplified Endurance Function Model. Advances in Mechanical Engineering. 2013;2013:pp. 12. 
[40] Susmel L, Taylor D. An Elasto-Plastic Reformulation of the Theory of Critical Distances to Estimate Lifetime of Notched Components Failing in the Low/Medium-Cycle Fatigue Regime. Journal of Engineering Materials and Technology. 2010;132:021002.

[41] Kamal M, Rahman MM, Rahman AG. Fatigue life evaluation of suspension knuckle using multi body simulation technique. Journal of Mechanical Engineering and Sciences. 2012;3:291-300.

[42] Rahman MM, Ariffin AK, Abdullah S, Noor MM, Bakar RA. Durability assessment of cylinder block for two stroke free piston linear engine using random loading. American Journal of Applied Sciences. 2009;6:726-35.

[43] Manning R, Ewing, J. (2009). .RACQ Vehicles Technologies. Temperatures in cars survey. RACQ Vehicles Technologies. 2009:1-21. 